\begin{tabular}{|c|}
\hline ARTIGO \\
Recebido em: \\
$12 / 08 / 2014$ \\
\\
Aceito em: \\
$23 / 10 / 2014$ \\
\end{tabular}

Encontros Bibli: revista eletrônica de biblioteconomia e ciência da informação, v. 19, n.41, p. 59-82, set./dez., 2014. ISSN 1518-2924. DOI: 10.5007/1518-2924.2014v19n41p59

\title{
A competência informacional para seleção e disseminação do acervo literário infantil da biblioteca pública municipal Barreiros Filho: olhar estético Information literacy for selection and dissemination of children's literary collection of municipal public library "Barreiros Filho": an esthetic view
}

\author{
Evandro Jair DUARTE 1 \\ Claudete Terezinha da MATA ${ }^{2}$ \\ Clarice Fortkamp CALDIN ${ }^{3}$
}

\begin{abstract}
RESUMO
Registra o potencial da literatura infantil e a responsabilidade da Biblioteca Pública em selecionar as obras que irão compor o acervo infantil, além de oportunizar o contato do livro com o público leitor. Informa acerca do funcionário da biblioteca e a importância do desenvolvimento da Competência Informacional e explora a dimensão estética dessa competência. 0 objetivo geral é verificar as habilidades, os comportamentos e as atitudes (competências) do Bibliotecário da Biblioteca Pública Municipal Barreiros Filho no processo de seleção disseminação do acervo literário infantil como forma de promoção e incentivo à leitura. Como objetivos específicos listam-se: a) verificar se há um bibliotecário para atendimento específico ao usuário infantil; b) registrar quem é o profissional responsável pela seleção das obras infantis da biblioteca pesquisada; c) descrever a relação entre funcionário da biblioteca e usuário; d) registrar as atividades desenvolvidas para que ocorra a circulação e disseminação do acervo infantil; e) registrar como ocorre a interação entre criança e livro; f) observar a Competência Informacional do funcionário da biblioteca para o trabalho com o acervo infantil. É uma investigação de caráter descritivo e exploratório e de abordagem qualitativa. A pesquisa tem um viés fenomenológico e se caracteriza como estudo de caso. Utilizou-se a entrevista face a face para a coleta de dados e como apresentação de resultados optou-se pela categorização das informações.
\end{abstract}

PALAVRAS-CHAVE: Funcionário de biblioteca. Biblioteca Pública Municipal Barreiros Filho. Acervo literário infantil. Dimensão Estética da Competência informacional.

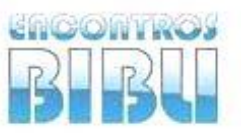

v. 19, n. $41,2014$. p. $59-82$

ISSN 1518-2924

\footnotetext{
1 Biblioteca Pública de Santa Catarina - dujaev@gmail.com

2 Universidade Federal de Santa Catarina - claudetedamata@gmail.com

${ }^{3}$ Universidade Federal de Santa Catarina - clarice@cin.ufsc.br
} 


\begin{abstract}
Records the potential of children's literature and the responsibility of the Public Library in selecting the works that will make the child collection, and provide the opportunity for contact with the book reading public. Informs about the official library and the importance of the development of Information Literacy and explores the aesthetic dimension of this competency. The overall objective is to verify the skills, behaviors and attitudes (competencies) of the Librarian of the Public Library Municipal "Barreiros Filho" in the selection dissemination of children's literary collection process as a way to promote and encourage reading. How to list specific objectives are: a) check for a specific librarian for child care user; b) professional record who is responsible for the selection of children's books of the searched library; c) describe the relationship between library staff and users; d) record the activities for which the circulation and dissemination of child collection occurs; e) register as the interaction between child and book occurs; f) observe Informational Competence of library staff to work with the children's collection. It is an investigation of descriptive and exploratory and qualitative approach. The investigation has a phenomenological bias and is characterized as a case study. The interview was used for the face to face data collection and presentation of results as we opted for categorizing information.
\end{abstract}

KEYWORDS: Official library; Municipal Public Library "Barreiros Filho"; Children's literary collection; Aesthetic dimension of Information Literacy.

\title{
1 INTRODUÇÃO
}

A literatura infantil (integrada a outras formas de expressão de linguagem escrita ou falada), responsável pela potencialização do desenvolvimento humano da criança na sua constituição de indivíduo socialmente cultural e participativo, é permeada por elementos que proporcionam e despertam no leitor o gosto pela leitura.

Nela pode-se perceber o fantástico, o maravilhoso, o doméstico, o cotidiano, a capacidade de criação e a imaginação em plena atividade. Permite a presença de reis, fadas, seres humanos e bichos interagindo entre si. Nesse contínuo, a transformação do mundo por personagens insólitas ganha vida própria no imaginário humano, especialmente no leitor infantil, ainda livre para pensar as formas e as palavras narradas.

Longa é a trajetória de todas as viagens ao mágico mundo das histórias infantis e de suas maravilhosas informações (expressões das personagens, cenários, etc.) complementadas por ilustrações. De fato, no livro infantil, as ilustrações, merecem requinte. Elas são importantes para enriquecer e dar qualidade ao livro. A criança tem os sentidos - visão, tato, olfato, paladar e audição - apurados e os utiliza em diversas atividades de recreação e entretenimento. Sendo assim, se um livro possui efabulação escrita de maneira 
agradável, ilustração bem feita e que chame a atenção da criança ou qualquer outro elemento inovador para enriquecer a composição da história (figuras que saltam das páginas dos livros, cheiro, entre outros) - ele pode ser atrativo para uma criança. Lembra-se aqui que outros entretenimentos para a criança concorrem com o livro - revistas, jogos, televisão, internet, brinquedos, só para citar alguns.

Escritores têm se especializado nesse tipo de literatura e se esmeram em apresentar textos de qualidade estética. Outros, porém, esquecem-se de que o público infantil é exigente, que espera certa densidade textual, personagens dinâmicas, situações emocionantes, fatos que induzem à reflexão.

Assim, o bom escritor é aquele que pensa nos interesses de seu público. Seu livro contém todos os elementos da narrativa: enredo, personagens, tempo, espaço, ambiente, narrador, etc. 0 escritor de textos literários infantis vale-se, na maioria das vezes, do conto, ou seja, de uma narrativa curta.

Lembra Gancho (2000) que a condensação e redução de determinados elementos não prejudica a narrativa, desde que o enredo apresente uma estrutura coerente, lógica. Dessa feita, o princípio da verossimilhança aristotélico ainda é válido (a história deve apresentar credibilidade) e o conflito deve existir como elemento estruturador da narrativa, deslizando do começo ao fim da trama. Sem o conflito a história não gera tensão, não produz prazer e não cativa o leitor.

É esse tipo de narrativa, curta e sedutora, que caracteriza o livro infantil de qualidade. Para produzi-lo, o escritor se reveste de modéstia (não apresenta excessos) e cria, no discurso ficcional, uma nova realidade. Se conseguir: explorar a função poética da linguagem; apresentar um texto de prazer, intemporal e universal; permitir ao leitor engajamento no mundo; mostrar uma linguagem falante (produtora de novos significados), fazer um desvio da linguagem usual (valer-se da literariedade); elaborar um enredo que interesse à criança; adornar o texto com ilustrações; e instigar a criança a reler a história ou ler outras histórias, o escritor está no caminho certo - seu produto será um livro de literatura infantil. 
Vários são os espaços em que o livro pode ser encontrado. Um deles é a biblioteca. O foco deste estudo está no ambiente da Biblioteca Pública, em especial na Biblioteca Pública Municipal Barreiros Filho do município de Florianópolis-SC e na seleção e disseminação do acervo do livro de literatura infantil, ou seja, obras ficcionais que interessam à criança.

Conforme ressalta o Manifesto da UNESCO sobre Bibliotecas Públicas, é fundamental estimular a imaginação e criatividade das crianças e dos jovens. (INTERNATIONAL..., 1994). Isso ocorre por meio da leitura, que promove o desenvolvimento das competências do indivíduo, em especial, as ligadas à dimensão estética da competência informacional, aquela ligada ao processo cognitivo, imaginativo, criativo e aspectos de solidariedade e sensibilidade humana (ORELO; VITORINO, 2012).

Dessa feita, os profissionais que contribuem para a seleção e disseminação do acervo da coleção infantil necessitam ter em mente duas questões básicas: a) refletir sobre autores, títulos, ilustrações (entre outros aspectos relacionados à autoridade da obra na escolha de um material de qualidade para o público infantil); b) planejar ações culturais que pretenda trabalhar em um período, que pode ser de longo, médio e curto prazo (BIBLIOTECA NACIONAL (BRASIL), 2010).

Ser um profissional competente no que faz é desenvolver habilidades para atender aos seus usuários e ter atitudes e comportamentos que promovam a ação de sugerir soluções para as demandas informacionais; precisa saber quando uma informação é necessária (AMERICAN LIBRARY ASSOCIATION ALA, 1989). A esse respeito, pode ser realizada a reflexão acerca da Competência Informacional do profissional da Biblioteca Pública Municipal Barreiros Filho.

Por Competência Informacional, Dudziak (2003, p. 28, grifo nosso) entende ser "o processo contínuo de internalização de fundamentos conceituais, atitudinais e de habilidades necessário à compreensão e interação permanente com o universo informacional e sua dinâmica, de modo a proporcionar um aprendizado ao longo da vida". 
Trabalhar com o acervo infantil é trabalhar simultaneamente com o clássico e com o novo. As mudanças nas temáticas de interesses do usuário infantil são rápidas, assim como o mundo ao seu redor. Assim sendo, há a necessidade de o profissional da biblioteca ter a preocupação em manter seus conhecimentos atualizados, bem como aprimorar as suas habilidades pessoais.

Concorda-se com Vitorino (2007, p. 61) quando esta conceitua, de forma basilar, a competência. Para a autora, trata-se de

[...] uma capacidade de agir eficazmente em um tipo de situação, capacidade esta que se apóia (sic) em conhecimentos, mas não se reduz a eles, pois as competências utilizam, integram, mobilizam conhecimentos para enfrentar um conjunto de situações complexas e o mais importante: implicam também em uma capacidade de atualização de saberes.

Selecionar uma obra literária para formar um acervo voltado ao usuário infantil é um trabalho que exige uma base de conhecimentos prévios, um saber antecipado do tipo de literatura que a criança gosta de ler, um reconhecimento do que há disponível no mercado, bem como manter seus conhecimentos profissionais atualizados. No trabalho de disseminar a literatura, o ideal é que o profissional da biblioteca tenha realizado uma leitura das obras da biblioteca que oferece para as crianças. Para o bom desenvolvimento da Competência Informacional é fundamental um equilíbrio entre as suas quatro dimensões: técnica, estética, ética e política.

Resumidamente, pode-se dizer que a dimensão técnica é aquela que se reporta a uma ação desenvolvida, uma certa forma de fazer essa ação, com demonstração de habilidade (RIOS, 2010), uma atividade prática e de caráter objetivo, revelada no cotidiano do executor (VITORINO; PIANTOLA, 2011). Já a dimensão estética reporta à presença de sensibilidade e beleza no saber fazer profissional (RIOS, 2010), ela promove ações que possam desenvolver a sensibilidade, bem como a criatividade e o pensamento crítico e reflexivo dos seres humanos (ORELO; VITORINO, 2012). Em relação à dimensão política observa-se um movimento da sociedade em uma construção coletiva, bem como o desenvolvimento de exercícios para o conhecimento de direitos e deveres dos cidadãos (RIOS, 2010), pela ampliação dessa dimensão os viventes dessa sociedade podem participar de decisões e transformações nas formas de um 
viver social, exercendo a sua cidadania (VITORINO; PIANTOLA, 2011). Na dimensão ética arrola-se a orientação de ações humanas, baseadas em respeito e solidariedade, com vistas ao realizar o bem coletivo (RIOS, 2010); a ética perpassa todas as dimensões da Competência Informacional, ela tem a função pedagógica de transformar os homens em cidadãos (VITORINO; PIANTOLA, 2011).

O objetivo geral desta pesquisa é verificar as habilidades, os comportamentos e as atitudes (competências) dos funcionários da Biblioteca Pública Municipal Barreiros Filho no processo de seleção e disseminação do acervo literário infantil como forma de promoção e incentivo à leitura. Como objetivos específicos estão: a) verificar se há um bibliotecário para atendimento específico ao usuário infantil; b) registrar quem é o profissional responsável pela seleção das obras infantis da biblioteca pesquisada; c) descrever a relação entre funcionário da biblioteca e usuário; d) registrar as atividades desenvolvidas para que ocorra a circulação e disseminação do acervo infantil; e) registrar como ocorre a interação entre criança e livro; f) observar a Competência Informacional do funcionário da biblioteca para o trabalho com o acervo infantil.

Para o desenvolvimento da investigação de caráter descritivo e exploratório optou-se pela abordagem qualitativa. Segundo Creswell (2010, p. 26) “a pesquisa qualitativa é um meio para explorar e para entender o significado que os indivíduos ou os grupos atribuem a um problema social ou humano". De acordo com Minayo (2012, p. 21) a pesquisa qualitativa "responde a questões muito particulares", é o tipo de pesquisa que "trabalha com o universo dos significados, dos motivos, das aspirações, das crenças, dos valores e das atitudes". Diante do exposto foi que se escolheu a abordagem qualitativa para a pesquisa.

Por se tratar de uma investigação da realidade representada pelo sujeito da pesquisa, esta terá um viés fenomenológico, que segundo Triviños (2010, p. 43) "é o estudo das essências" e ocupa-se em descrever a partir da visão pessoal ou da experiência do mundo, pois "todo o universo da ciência é construído sobre o mundo vivido". 
Optou-se por investigar a Biblioteca Pública Municipal Barreiros Filho da Grande Florianópolis-SC - assim, essa pesquisa se configura, também, como estudo de caso, que de acordo com Gil (1993, p. 58), é "um estudo profundo e exaustivo de um ou de poucos objetos, de maneira que permita o seu amplo e detalhado conhecimento".

Para a coleta de dados foi feita a entrevista face a face com o profissional que atua na biblioteca. A respeito da entrevista, Minayo (2012) considera ser a matéria-prima a fala de alguns interlocutores. Segundo essa mesma autora, "na pesquisa qualitativa, a interação entre o pesquisador e os sujeitos pesquisados é essencial" (MINAYO, 2012, p. 63). Na entrevista foi solicitado o preenchimento do Termo de Consentimento Livre e Esclarecido - TCLE, em que consta o título da pesquisa, os objetivos e a solicitação para uso do nome da biblioteca. A auxiliar de biblioteca que trabalha no setor de processamento técnico da biblioteca foi quem assinou o TCLE e respondeu às perguntas dos pesquisadores.

\section{A COMPETÊNCIA INFORMACIONAL PARA A SELEÇÃO E A DISSEMINAÇÃO DO ACERVO LITERÁRIO INFANTIL DA BIBLIOTECA PÚBLICA MUNICIPAL BARREIROS FILHO}

A Biblioteca Pública Municipal Barreiros Filho tem sede à Rua João Evangelista da Costa, no bairro Estreito do Município de Florianópolis no Estado de Santa Catarina. Conta com aproximadamente 20 pessoas em seu quadro funcional, sendo dezoito assistentes administrativos, dois estagiários (um do nível médio e outro do nível superior do curso de Biblioteconomia da Universidade Federal de Santa Catarina-UFSC); desses profissionais, uma das assistentes administrativos trabalha no setor de processamento técnico, local de processamento técnico dos livros para serem incluídos no sistema de gerenciamento do acervo. Ela tem a formação em Biblioteconomia, porém, não é a bibliotecária responsável pela instituição pesquisada, pois na Prefeitura Municipal de Florianópolis-SC não há o cargo de bibliotecário. 
Ao entrar na biblioteca, pode-se encontrar à esquerda a recepção com o serviço de empréstimo e devolução de obras do acervo; após e na mesma direção está a sala da direção; e ao seguir pela esquerda encontram-se algumas salas que são para a ministração de cursos (legislação portuária, danças, patch colagem, grampada, entre outros); ainda no térreo e à esquerda está o acervo em Braille com livros e áudios, discos de vinil para empréstimos, cd's, Dvd's, outros; o setor infantil fica após o acervo de Braille, nas prateleiras. Os livros infantis estão disponibilizados com tarjas de cores vermelha, verde, azul e preta, para indicação da faixa etária das crianças, como forma de auxiliar na indicação de leitura das obras. Nesse espaço há uma televisão com dvd em que a criança pode selecionar o disco com o filme ou desenho que deseja assistir e solicitar que um funcionário coloque para ela. Estão, também, disponíveis para empréstimos gibis variados. No hall central da entrada encontra-se uma mesa com livros para a realização do troca-troca de livros (consiste em levar um livro e trocar por outro que esteja na mesa disponível para essa permuta); ainda no hall, há uma exposição de quadros que podem ser adquiridos por meio de compra, e; do lado direito de quem entra na biblioteca há um auditório onde são exibidos filmes e encenações teatrais para as crianças (outros eventos acontecem neste espaço).

$\mathrm{Na}$ instituição trabalha-se com o projeto intitulado de Biblioteca itinerante, que faz a aproximação dos livros e comunidades carentes por meio do atendimento aos pacientes do Hospital Florianópolis que também está localizado no bairro Estreito. As obras são repostas quinzenalmente nas dependências do hospital. Outra ação é a realização de atividades no Quintal Cultural como recital de piano, apresentação de grupo de samba de raiz. Cumpre lembrar que a direção e demais profissionais da biblioteca permitem a grafitagem feita por artistas plásticos em suportes específicos para a ação e disponibilizam livros para os que transitam por ali poder levar para casa ou ler nos tapetes, nas almofadas ou nos bancos do quintal.

O setor infantil da biblioteca, objeto deste estudo, conta com acervo para crianças de menos de um ano de idade a adolescentes e jovens. Trata-se de um acervo infanto-juvenil. É um espaço regularmente frequentado por tal público 
em busca de histórias narradas em gibis atuais e best-sellers, que são os mais procurados.

A biblioteca recebe no setor infantil turmas de escolas em datas comemorativas com atividades pertinentes ao tema, as quais recebem um brinde ao final das ações do dia.

Pode-se dizer que o acervo tem as suas limitações como outras Bibliotecas Públicas, e que sua composição ocorre com o recebimento de doações.

Feita a descrição do ambiente da pesquisa, a seguir apresenta-se o resultado obtido na entrevista com a profissional que é assistente administrativa. Para tal, optou-se pelo uso de categorias, que são: a) a seleção das obras do acervo; b) a relação entre funcionário da biblioteca e usuário; c) a disseminação do acervo literário infantil; d) a preocupação com a criança e o livro; e) o funcionário da biblioteca, a leitura e a atualização de saberes. A entrevista foi realizada no mês de dezembro do ano de 2013. As perguntas foram elencadas como seguem:

1. A seleção do acervo é feita por uma comissão ou por um bibliotecário?

2. Quais as estratégias que a comissão ou o bibliotecário utiliza para selecionar os títulos e os autores das obras para compor o acervo infantil?

3. Para você o que representa a qualidade em um livro infantil?

4. Na biblioteca há um profissional para o atendimento ao público infantil?

5. Quais são as atividades que a biblioteca desenvolve para o público infantil?

6. Qual é o objetivo de cada atividade proposta ao público infantil?

7. Após as atividades com o livro e as histórias há um espaço para o diálogo entre o profissional da biblioteca e as crianças?

8. Como você observa a relação profissional e usuário?

9. Qual a importância que a literatura infantil tem para as crianças?

10. Na biblioteca há um momento para a leitura solitária?

11. As crianças que frequentam o espaço infantil têm a liberdade de entrar quando querem e de escolher o que desejam ler? 
12. 0 que pode contribuir para o bem estar no espaço infantil?

13. Os livros infantis podem contribuir para a relação social da criança com outros indivíduos?

14. Você considera ser possível analisar a sociedade por meio da leitura lúdica, maravilhosa e fantástica?

15. Você consegue identificar o momento da identificação da criança com a história trabalhada na biblioteca? (lida, narrada, contada...)

16. As crianças, após a apresentação da história, têm se apropriado de características de alguma personagem?

17. Para você, o livro infantil tem um poder terapêutico?

18. Você já leu um livro que aliviou seu coração, que te tocou? (exceto autoajuda)

19. Com que frequência você atualiza os seus conhecimentos?

20. Quais são as habilidades necessárias para o atendimento e a promoção da leitura do acervo infantil?

\subsection{A seleção das obras do acervo}

No tocante ao questionamento acerca do profissional responsável pela seleção do acervo da biblioteca, a assistente administrativo respondeu que "é realizada por uma auxiliar de biblioteca 4 responsável" por esse serviço e que conta com a ajuda de um estagiário desde 2013. Essa funcionária trabalha no setor de processamento técnico com recebimento de doações, seleção, processamento, armazenamento e o descarte. Não há na instituição um bibliotecário que seja responsável por ela.

O trabalho de seleção não é feito por uma comissão composta por representantes do quadro funcional da biblioteca, usuários e pessoas da comunidade. Quem realiza essa atividade é a assistente administrativo lotada no setor de processamento técnico, ela faz toda a tarefa em parceria com o estagiário (aluno do curso de Biblioteconomia da UFSC).

\footnotetext{
${ }^{4} \mathrm{Na}$ fala da entrevistada ela utiliza o termo "auxiliar de biblioteca" por ser este muito utilizado no ambiente de bibliotecas para representar quem trabalha nesses espaços e não tem a formação em biblioteconomia. No entanto, o cargo correto é assistente administrativo.
} 
Para a seleção do acervo de uma biblioteca a assistente administrativo necessita desenvolver a dimensão técnica da Competência Informacional e dotar-se de saberes para reconhecer aspectos como a "qualificação do autor; idoneidade do editor; relevância do assunto ou tema; mérito literário; exatidão das informações contidas no texto, aspectos físicos: boa encadernação, qualidade do papel, qualidade de impressão, ilustrações, existência de índices; e sempre a última edição publicada" (CÔRTE; BANDEIRA, 2011, p. 61). Weitzel (2000) reforça esses critérios com outros, como: atualidade, cobertura/conteúdo, objetividade e precisão.

Algumas estratégias podem ser adotadas para consultar o material a ser adquirido, como o uso de

catálogos de livreiros e editores; resenhas (recensões) de livros em periódicos; seções literárias em revistas e jornais; visitas a livrarias e editoras; indicações de alunos e professores; análise das estatísticas de uso do acervo; ferramentas de busca na internet; consulta a bases de dados especializadas disponíveis na internet (CÔRTE; BANDEIRA, 2011, p. 61-62).

Ao questionar a funcionária da biblioteca acerca das estratégias adotadas pela assistente administrativo do setor de processamento técnico para selecionar os títulos e os autores das obras para compor o acervo infantil a resposta foi que ela "utiliza seleção por obras de autores clássicos e obras que geralmente os usuários procuram".

Percebe-se que no caso da Biblioteca Pública Municipal Barreiros Filho o uso das recomendações feitas por autores da área são seguidas parcialmente, quase que infimamente, pois a assistente administrativo e o estagiário se baseiam em sugestões de usuários, autoridade renomados, lançamentos, primam pelas atualizações das edições dos livros, boa qualidade de papel e impressão, atualidade das matérias e boa encadernação.

\subsection{A relação entre funcionário da biblioteca e usuário}

O público de uma biblioteca volta a utilizar seus serviços e seu ambiente diante da necessidade de informação para uma resposta a um questionamento de pesquisa. Ou, então, para o entretenimento próprio com a busca de livros de literatura que o agrada. 
Esse local necessita ser aprazível e com mobiliário adequado, com assentos confortáveis para possibilitar uma permanência maior, até mesmo ter almofadas ou puffs espalhados para quem quiser deitar. Em se tratando de crianças, a ludicidade é fundamental. Os pequenos leitores gostam de figuras, cores, novidades e a permissão para ler onde e como quiserem.

A relação entre o funcionário da biblioteca e usuários foi questionada para se conhecer como esse encontro ocorre na Biblioteca Pública Municipal e a entrevistada informou que não há um profissional na instituição com dedicação exclusiva para o setor infantil. Dessa forma, ela diz que "como não há profissional qualificado, o contato é para agradar e fazê-los retornar ao ambiente da Biblioteca. A Biblioteca tem a preocupação com o 'setor infantil' [...] há preocupação com esse espaço. Todos querem receber bem as crianças e fazemos o possível para que elas saiam da Biblioteca, felizes".

Assim, esclareceu-se não haver um funcionário que esteja com a atribuição exclusiva e dedicada para o atendimento e disseminação do acervo literário infantil. Os assistentes administrativos que trabalham na biblioteca es estagiários se revezam para atender aos usuários que circulam no espaço institucional ou para receber e orientar às marcações de visitas feitas por escolas com o intuito de utilizar o acervo infantil.

Nesse contexto, as habilidades, as atitudes, os valores e os conhecimentos dos funcionários da biblioteca da Biblioteca Pública Municipal Barreiros Filho fazem parte da Competência Informacional desses. Dessa forma, torna-se possível perceber a dimensão estética desse tipo de competência. A Estética é vista como a presença do belo, percebido e representado no agir humano, em especial permeado nos elementos, tais como sensibilidade e beleza constituintes do saber e do fazer profissional. Rios (2010, p. 97) corrobora com esse pensar ao afirmar que "a sensibilidade e a criatividade não se restringem ao espaço da arte. Criar é algo interligado a viver, no mundo humano. A estética é, na verdade, uma dimensão da existência, do agir humano".

Perguntado acerca das habilidades necessárias para o atendimento e para a promoção da leitura do acervo infantil da Biblioteca Pública Municipal, a resposta traz à memória a reflexão de Pennac (1998, p. 33) quando ele trata da 
exigência com a leitura, da defesa de que é preciso ler. Percebe-se na fala da auxiliar de biblioteca que a orientação de "partilhar sua própria felicidade de ler" é uma prática nessa instituição. Principalmente quando ela diz: "o livro infantil só sai das estantes se você souber empolgar alguém pela leitura radiante que ele pode ter. Conhecer o livro é fundamental. Saber o final da história é provocar a criança à leitura do que há no acervo infantil”.

Quando ela afirma que o livro só sairá das estantes quando alguém for empolgado para fazer essa retirada, percebe-se que a mediação pode ser feita por essa auxiliar de biblioteca por meio de sua experiência com as suas próprias leituras do que consta no acervo local. A profissional ainda afirma que é preciso conhecer o material que será oferecido à criança. Esse compartilhar de informações pode contribuir para o incentivo à leitura e demonstra a sensibilidade da funcionária da biblioteca para com os interesses dos leitores. Ela diz que a "capacidade de identificação de itens por idade, interesses dos leitores" possibilita a aproximação do usuário com materiais que vão ao encontro com o desejado por cada indivíduo. Essa relação feita pela mediação da leitura tem o poder de auxiliar na aproximação das pessoas que frequentam o local em busca de uma obra que atenda às suas necessidades com o acervo da biblioteca.

\subsection{A disseminação do acervo literário infantil}

Diversas são as formas de divulgação do acervo de uma biblioteca. Algumas atividades podem contribuir para essa atividade. Os pesquisadores deste trabalho perguntaram à funcionária da biblioteca quais eram as atividades que a biblioteca desenvolve para o público infantil e a resposta foi: "teatro, contações de histórias, interpretações pelas crianças em eventos. Em algumas datas comemorativas, as crianças dos colégios públicos e privados são convidadas a assistirem espetáculos teatrais, circenses, e depois fazerem a reprodução do que assistiram. Há, também, situações em que as crianças vêm para escolher livros e ficam lendo livremente no espaço dedicado exclusivamente para elas". 
O trabalho com a mediação da leitura e a oportunidade de disponibilizar o acervo, possibilita que os usuários utilizem o espaço da biblioteca para "diversas atividades lúdicas em momentos adequados", essa ação diferenciada de profissionais atuantes em bibliotecas é vista com "um diferencial para quem a visita" (SILVA; SANTOS, 2014, p. 9).

A ação cultural em bibliotecas tem o poder de trazer para esse ambiente uma série de manifestações de cultura a um público que "busca por novidades, e apresenta uma abertura para a realização de atividades", bem como possibilita a troca entre profissionais de outras áreas, como pedagogos, psicólogos, dançarinos, músicos, entre outros (SILVA; SANTOS, 2014, p. 9).

Observa-se que há uma variedade de ações executadas nas dependências da Biblioteca Pública Municipal pesquisada e que essas atividades trazem o leitor para perto das histórias. A esse respeito, a funcionária da biblioteca foi questionada em relação ao objetivo de cada atividade proposta ao público infantil e a resposta foi a seguinte: "É conseguir que compareçam na Biblioteca".

Quando o objetivo é atingido, as visitas são frequentes; pode-se afirmar que essa instituição consegue cumprir essa missão. A funcionária explicita que “a visita à Biblioteca é nosso maior desafio; pois é através da visita que conseguimos criar as condições para bons leitores. Aqueles que vêm conhecer o nosso espaço infantil ficam encantados e retornam com frequência. Há leitores infantis que retiraram de empréstimos mais de 30 livros durante o ano".

Com as visitas, o material da composição do acervo circula pela comunidade que a biblioteca atende. As crianças, também, são disseminadoras da coleção de livros. Elas conversam umas com as outras e sugerem títulos e autores. Outra questão da entrevista era se após as atividades realizadas com livros e histórias no local da biblioteca existia um espaço para a fala e o diálogo entre o profissional e as crianças. A funcionária da biblioteca respondeu: "geralmente, o contato com as crianças, após a leitura é no balcão, onde perguntamos o que gostaram do livro e incentivamos a voltar [...] e marcamos o retorno para perguntarmos o que mais gostaram. Muitas contam as histórias e há momentos que sentimos as interações das crianças que vêm buscar livros, dando opiniões às outras que estão no espaço infantil." 
A conversa com os pequenos leitores para conhecê-los e oportunizar esse tipo de troca de informações entre eles possibilita a interação social dos usuários, bem como a circulação do acervo com indicações feitas pela funcionária e por outras crianças.

\subsection{A preocupação com criança e o livro infantil}

A criança é um "ser-no-mundo social", como diria o filósofo francês Merleau-Ponty (apud MATTHEWS, 2010) e no mundo vive as suas próprias experiências, percebe e descobre coisas. Por meio da leitura está a possibilidade de desenvolver e ampliar a sua cognição e seus conhecimentos de ser, do outro e de mundo.

É ser consciente do mundo enquanto algo partilhado com outros seres humanos que são sujeitos como nós, com os quais partilhamos os significados dados aos objetos naturais e culturais e com os quais podemos, desse modo, nos comunicar (MATHEWS, 2010, p. 152).

Trata-se de uma leitura de mundo, tomar consciência que uma ação política e democrática com outros sujeitos por meio da apropriação e comunicação de saberes. Dessa feita, surge a questão feita à funcionária da Biblioteca Pública Municipal: Qual a importância da literatura infantil para as crianças?

E a resposta foi: "o despertar da criança começa com a leitura. Bons leitores são seres humanos criativos; com mentes abertas. Conversam e se expressam com qualidade vocal e são sentimentalmente empolgadas com a vida. Têm consciência aberta para colocar suas opiniões e, com frequência, não podem ser manipulados, pois, têm conhecimento e repertório próprio para o convencimento".

Assim, ler possibilita a criatividade e diálogos com questionamentos e opiniões embasados em conhecimentos previamente adquiridos. A leitura permite a reflexão e conexão com o mundo ao redor. As crianças que leem permitem-se aprender e, a esse respeito, de acordo com Orelo e Vitorino (2012, p. 47), “0 'aprender a aprender', pode-se dizer, é a essência para o desenvolvimento humano e permite que o cidadão adquira habilidades 
cognitivas, comece a pensar criticamente, o que, por sua vez, é fundamental para o exercício da cidadania."

Esses primeiros exercícios da leitura que a criança realiza é um passo para a sua formação intelectual, o que permitirá a formação de ideias e posicionamento diante de fatos e acontecimentos em sua caminhada de vida.

Como a leitura tem seus lugares e seus leitores diversos, pode-se afirmar que a biblioteca é o lugar desse exercício e, ainda, possibilita trocas. Como também possibilita o momento de ler em silêncio. Permite que o leitor fique em um isolamento proposital para essa finalidade - a intimidade com o texto.

Nesse tocante, os pesquisadores interrogaram se na Biblioteca Pública Municipal Barreiros Filho existia um espaço e um momento para a leitura solitária, caso o usuário desejasse. Segundo a funcionária da biblioteca, "na Biblioteca, as crianças têm um espaço para deitarem e usufruírem da leitura. Também proporcionamos isso no 'quintal cultural', onde os livros são expostos no jardim da Biblioteca, e as crianças sentem-se livres para escolher um título, deitar no tapete estendido e lerem o que desejam. Podem, simplesmente, escolher e folhear os livros".

Essa Biblioteca Pública estudada é um espaço democrático e de possibilidades, configura-se como um espaço criativo, pois permite a sensibilidade e o belo nas expressões e nas manifestações culturais realizadas em seu ambiente. As crianças frequentam o espaço infantil e têm a liberdade de entrar quando quiserem e de escolher o que desejarem para a leitura. Essa afirmativa se baseia nas palavras da entrevistada: "As crianças têm toda liberdade de escolherem os livros, entrarem quando querem. Nós adoramos quando vemos nosso público infantil empolgado com o espaço infantil”.

Compreende-se que para tentar conseguir fazer o encontro da criança com o livro seja necessário providenciar um espaço que seja de deleite, que possa contribuir para o bem estar no espaço infantil. A esse respeito, a funcionária entrevistada informa que uma das táticas para a qualidade nos produtos e serviços está na "boa qualidade do acervo. A empolgação daqueles que oferecem os títulos. Uma profissional apta para atuar no 'espaço infantil' é 
fundamental para a contribuição do bem estar e do estar bem em seu espaço de leitura, de conhecimento, de lazer e de criação".

Com respeito à fala transcrita anteriormente, pode-se refletir que a funcionária da biblioteca atuante no setor de processamento técnico em conjunto com outra funcionária e com o estagiário do curso de Biblioteconomia seleciona obras para o acervo infantil; são obras que possuem uma qualidade de escrita e gráfica, com autores renomados e ilustradores que agradam as crianças. 0 que permite o planejamento e o desenvolvimento de atividades para serem apresentadas ao público como produtos que estão vinculados ao uso do acervo (ações culturais). No entanto, o que falta para o ambiente da biblioteca é um profissional que esteja disponível e apto a trabalhar com o público infantil nessas atividades planejadas. Segundo a funcionária, já em conversa informal, as funcionárias da biblioteca que atuam no setor infantil são pedagogas de formação, que estão no quadro funcional como assistente administrativo.

Nesse espaço lúdico as crianças utilizam a biblioteca, o acervo e demais espaços (quintal, parque externo, salas de estudos e de cursos, entre outros). 0 público infantil lê, percebe que o local é agradável e possibilita sentar, deitar, entre outras formas de ler e manifestação de seu desejo para o uso do espaço, tudo dentro da ordem e das normas da instituição. Também percebe que pode interagir com outros colegas e com as histórias narradas ou lidas - o que pode permitir que os pequenos usuários tenham o prazer em retornar ao ambiente da biblioteca.

Nesse contexto, perguntou-se para a entrevistada se ela conseguia observar o momento de identificação da criança com a história apresentada (lida, narrada, contada) na biblioteca. Ela comenta que "a criança quando gosta da história, verbaliza sua visão sobre ela, e passa a criar outras abordagens a partir das narrações ouvidas". Ainda informa que as crianças, após a apresentação da história fazem a apropriação de características de alguma personagem, mas que em sua maioria não há condições que consigam permitir uma observação para perceber a "reação das crianças".

Diante de todo o exposto anteriormente, questionou-se a funcionária acerca de que forma os livros infantis podem contribuir para uma relação social 
da criança. Segundo ela, "as crianças, em seus encontros, possuem a capacidade de relacionamento. Os livros oportunizam as expressões e mostram caminhos diferentes". O livro consegue dar elementos para que os seus leitores se apropriem deles e os utilizem em seus "relacionamentos" sociais.

\subsection{0 funcionário da biblioteca, a leitura e atualização de saberes}

0 profissional que atua em biblioteca necessita ter consciência de que para um trabalho de qualidade é importante ter uma educação continuada. Dessa forma, ele poderá ter condições de conhecer as novidades dessa área de atuação e melhorar os seus produtos e serviços.

Dito isso, pode-se afirmar que o funcionário da biblioteca tem em suas atribuições rotineiras tarefas com características técnicas. Como visto, na biblioteca eleita para a pesquisa não há o bibliotecário como profissional atuante nas atividades técnicas, bem como nas demais ações da instituição. No entanto, a assistente administrativo que desempenha suas atividades diárias na Biblioteca Pública Municipal de Florianópolis-SC teve que desenvolver as habilidades que são fundamentais para que possam ser feitas as ações profissionais de seleção, aquisição, organização e disseminação das informações contidas nos diversos materiais da coleção do acervo.

Porém, outras dimensões de sua Competência Informacional necessitam de exercício, como a estética, a ética e a política. Quando se trata de profissão, as dimensões ética e política circundam todo o fazer técnico. Importa, neste trabalho, ater-se à dimensão estética, menos explorada e igualmente importante para a qualidade na prestação de serviços.

A dimensão estética pode ser vista como a arte do belo. Em outras palavras: pode-se perceber a criatividade e a presença da sensibilidade e da beleza no agir humano em seu saber e fazer profissional. "E se falamos em competência, não se trata de uma sensibilidade ou de uma criatividade qualquer, mas de um movimento na direção da beleza, aqui entendida como algo que se aproxima do que se necessita concretamente para o bem social e coletivo" (RIOS, 2010, p. 99). 
As questões técnicas para a formação do acervo ficam a critério da funcionária da biblioteca do setor de processamento técnico e do estagiário de nível superior (estudante de Biblioteconomia), e as atividades que envolvem as dimensões éticas, políticas e estéticas da Competência Informacional são desenvolvidas pelos demais funcionários da biblioteca.

Dessa feita, tenta-se registrar a percepção da funcionária acerca do livro e da leitura e suas possibilidades de expressão artística no meio social. Com respeito à sociedade, perguntou-se como analisá-la por meio da leitura dos contos maravilhosos. E para a entrevistada, "quando a sociedade conseguir ter a compreensão de que são os contos que viabilizam as circunstâncias produtivas para a análise do mundo, do espaço que vivemos, este será um espaço de transformação para um mundo de qualidade. Mundo onde valores emocionais serão mais importantes que valores econômicos".

A funcionária da biblioteca alerta para transformação para um mundo de qualidade em que os valores emocionais são importantes. Destaca-se aqui a sensibilidade e a percepção do poder da literatura. Ela pode exercer um poder terapêutico. E a esse respeito, os pesquisadores questionaram a profissional: Para você, o livro infantil tem poder terapêutico? A resposta foi a seguinte: “o livro infantil tem poder mágico: a viagem proporcionada é terapêutica. Ocupar a mente com uma boa leitura é voar livremente. E ser livre, sentir-se livre é estar bem. É ser feliz de forma simples”. A poesia está presente nas palavras dela.

Se o livro infantil tem um poder que para ela é mágico e possibilita a terapia por sua viagem, uma forma de liberdade e simplicidade para uma vida feliz, a pergunta a seguir foi direcionada às suas experiências enquanto leitora e participante da viagem lúdica do mundo literário. Perguntou-se a ela qual livro lido que a atingiu de maneira emotiva. A funcionária da biblioteca respondeu: “João e o Pé de Feijão. Na casa dos meus avós havia um enorme pé de feijão, e eu tinha um grande amigo chamado João. Nós brincávamos de esconder, mas eu sempre sabia que o encontraria entre o pé de feijão. Ficou na memória. Um grande amigo entre o pé de feijão. Sinto agora uma grande emoção de lembrar da casa de meus avós (hoje vendida) e da perda de um amigo que já está em outro plano". 
Na resposta, a funcionária fez uma análise de suas leituras e conseguiu voltar a um tempo e lembrou-se de situações vivenciadas por ela na casa da avó, local onde existiam dois elementos da história: o pé de feijão e o amigo João. A catarse ocorreu com a emocionada declaração dessa lembrança e por não haver mais a casa que foi vendida e pela perda do amigo na morte.

A narrativa da entrevistada em relação à sua experiência com a literatura de um livro em especial possibilitou que seus sentimentos fossem tocados e expostos. Assim, percebe-se que dessa vivência da funcionária da biblioteca, ao falar e expor o que sente ao lembrar-se da história faz parte da biblioterapia, defendida por Caldin (2001), quando aponta a literatura com função terapêutica, uma vez que o material ficcional proporciona a externalização de problemas emocionais e físicos.

No que tange à leitura para a atualização profissional ao longo da vida, perguntou-se acerca da frequência da atualização dos conhecimentos literários da respondente da entrevista. E o resultado foi: "Leio praticamente todos os dias. Adoro o acervo infantil, pois é minha área de formação. Sou pedagoga infantil. Amo livrarias. E quando fico no balcão da Biblioteca, leio as obras, pois assim posso dar sugestões para as crianças e adolescentes. Aprendi a ler com meu pai, ouvindo-o contar histórias para mim e meu irmão, dormir. Meu pai sempre dormia antes. E nós tínhamos que ler o livro para saber os finais".

Percebe-se, na fala da profissional, que ela é uma leitora assídua e tem gosto pelo livro e pelas histórias. Como palavras de incentivo aos leitores deste artigo, solicitou-se que ela deixasse um comentário pertinente à literatura na vida da criança. A narrativa foi parafraseada e alguns trechos foram utilizados na íntegra. Ela disse o seguinte: A literatura faz você "viajar pelo mundo, estando sentada num local calmo". Assim como, ela tem o poder de deixar sua "escrita ficar mais expressiva". Para quem lê, "as ideias [são] mais fascinantes" e podem abrir os horizontes. Segundo ela, "ler é viver. Ser feliz imaginando possibilidades da literatura é ter um caminho na vida para se guiar". Diz ainda que "a literatura faz desenvolver o intelecto. E o intelecto tem que ser provocado para vivermos mentalmente saudáveis". Ela faz uma reflexão acerca de sua experiência com a leitura e diz: "Penso que aprendi com meus pais e 
adoro fazer isso com meus sobrinhos. Sempre vamos às livrarias escolher livros e comentamos muito antes de adquiri-los. Sou extremamente feliz em ouvi-los, e várias vezes eu troquei de livros por sugestões deles. São leitores vorazes".

\section{CONSIDERAÇÕES FINAIS}

Neste trabalho foi possível discutir sobre a temática da Competência Informacional e explorar sua dimensão estética. Os profissionais que trabalham na Biblioteca Pública Municipal Barreiros Filho são assistentes administrativos com formações diversas, dentre eles está uma assistente administrativo com formação em Biblioteconomia, esta trabalha no setor de processamento técnico da instituição. Não é a bibliotecária da instituição porque não há esse cargo na Prefeitura de Florianópolis-SC e ela não poderia ser nomeada para ser essa profissional.

Essa profissional, assim como os demais que atuam nos espaços da biblioteca necessitam manter-se atualizados com as novidades tecnológicas, da leitura, do livro e da escrita. Nesse ponto, entra a Competência Informacional que tem o viés de aprendizado ao longo da vida.

Observa-se que a pesquisa conseguiu atingir seu objetivo geral que era verificar as habilidades, os comportamentos e as atitudes (competências) dos funcionários da Biblioteca Pública Municipal Barreiros Filho no processo de seleção e disseminação do acervo literário infantil como forma de promoção e incentivo à leitura.

Constatou-se que a assistente administrativo que trabalha no setor de processamento técnico é a funcionária da biblioteca responsável pela seleção das obras infantis. São obras oriundas de doações e chegam à biblioteca em grandes quantidades, para a seleção é necessário uma força tarefa com o auxílio de outros funcionários da biblioteca e do estagiário do curso de Biblioteconomia.

Dessa feita, o acervo já registrado e catalogado passa para as estantes e o que se pode perceber na fala da funcionária entrevistada, com relação ao uso da coleção, é que a relação entre funcionário da biblioteca e usuário é a de permitir 
a liberdade do uso dos espaços da biblioteca, tudo dentro das normas e da ordem necessária em ambientes públicos e comunitários. 0 atendimento às crianças é permeado pela sensibilidade e por atenção aos anseios dos pequenos leitores. Eles são orientados e atendidos de maneira que possibilite o desejo de voltar e frequentar o espaço.

No tocante às atividades executadas para promover o acervo e a leitura na Biblioteca Pública Municipal Barreiros Filho são as mesmas realizadas em outras instituições com a mesma missão, como: narração de histórias, apresentação teatral de histórias, desenho de elementos das histórias, releituras, entre outras ações. 0 que se percebe é que na instituição pesquisada tais atividades são planejadas e inseridas em um calendário da biblioteca, acontecem periodicamente, fogem das ações executadas em virtude de uma data comemorativa.

Visto que a biblioteca desenvolve diversas atividades ao longo do ano para promover a utilização do acervo em geral e mais especificamente o infantil, registra-se que para tal é importante que os auxiliares de biblioteca desse ambiente informacional tenham desenvolvido ao longo da vida diferentes habilidades para as ações executadas juntamente com os usuários.

Esses profissionais precisam ser dotados de atitudes e comportamentos que promovam o bem estar dos leitores no ambiente da biblioteca e a aproximação do público com o livro. Eles demonstram as suas competências com essas atuações.

Observou-se que não há um bibliotecário na instituição, assim como também não há um funcionário para o atendimento exclusivo ao usuário infantil. Quando uma criança ou outro usuário de faixa etária diferenciada comparece ao local é atendido por alguém que esteja à disposição.

Foi possível registrar que as diversas atividades que a Biblioteca Pública Municipal desenvolve com o intuito de fazer circular o acervo infantil são formas de disseminar as obras da coleção para o público interessado.

Registrou-se, também, a Competência Informacional da funcionária do setor de processamento técnico e dos demais funcionários para o 
desenvolvimento do trabalho com o acervo infantil. Dessa feita, pode-se atingir os objetivos específicos da pesquisa.

Porém, este assunto não se encerra por aqui, ele abre uma porta para que outras pesquisas sejam realizadas e investigadas sob outro olhar.

\section{REFERÊNCIAS}

AMERICAN LIBRARY ASSOCIATION - ALA. Presidential Committee on Information Literacy: final report. Washington, D. C., 1989. Disponível em: <http://www.ala.org/acrl/publications/whitepapers/presidential>. Acesso em: 04 ago. 2014.

BIBLIOTECA NACIONAL (BRASIL). Biblioteca pública: princípios e diretrizes. 2. ed. rev. e amp. Rio de Janeiro: FBN, 2010. (Documentos técnicos ; n.6).

CALDIN, Clarice Fortkamp. A leitura como função terapêutica: biblioterapia. Enc. Bibli: R. Eletr. Bibliotecon. Ci. Inf., ISSN 1518-2924, Florianópolis, Brasil, n.12, p. 32-44, 2001. Disponível em:

<https://periodicos.ufsc.br/index.php/eb/article/view/15182924.2001v6n12p32/5200>. Acesso em: 04 ago. 2014.

DUDZIAK, Elisabeth Adriana. Information literacy: princípios, filosofia e prática. Ci. Inf., Brasília, v. 32, n. 1, p. 23-35, jan./abr. 2003. Disponível em: <http://www.scielo.br/pdf/ci/v32n1/15970.pdf>. Acesso em: 04 ago. 2014.

INTERNATIONAL FEDERATION OF LIBRARY ASSOCIATIONS AND INSTITUTIONS - IFLA. Manifesto da IFLA/UNESCO sobre bibliotecas públicas. Netherlands, 1994. Disponível em: <http://archive.ifla.org/VII/s8/unesco/port.htm>. Acesso em: 04 ago. 2014.

GANCHO, Cândida Vilares. Como analisar narrativas. 7. ed. São Paulo: Ática, 2000.

GIL, Antonio Carlos. Como elaborar projetos de pesquisa.3. ed. São Paulo: Atlas, 1993.

MATTHEWS, Eric. Compreender Merleau-Ponty. Petrópolis: Vozes, 2010. Série Compreender.

MINAYO, Maria Cecília de Souza (org.). Pesquisa social: teoria, método e criatividade. 32. ed. Petrópolis: Vozes, 2012. (Coleção Temas Sociais).

ORELO, Eliane Rodrigues Mota; VITORINO, Elizete Vieira. Competência informacional: um olhar para a dimensão estética. Perspectivas em Ciência da Informação, v.17, n.4, p. 41-56, out./dez. 2012. Disponível em: 
<http://portaldeperiodicos.eci.ufmg.br/index.php/pci/article/view/1614/106 6>. Acesso em: 04 ago. 2014.

PENNAC, Daniel. Como um romance. Tradução de Leny Werneck. Rio de Janeiro: Rocco, 1998.

RIOS, Terezinha Azerêdo. Compreender e ensinar: por uma docência da melhor qualidade. 8.ed. São Paulo: Cortez, 2010.

SILVA, Maria Mônica da; SANTOS, Izabel Lima dos. Ação cultural em bibliotecas: conceitos e considerações. In: EREBD- ENCONTRO REGIONAL DOS ESTUDANTES DE BIBLIOTECONOMIA, DOCUMENTAÇÃO, CIÊNCIA E GESTÃO DA INFORMAÇÃO, 17., 2014, Fortaleza, CE. Anais eletrônicos... Fortaleza, CE: UFCE, 2014. Disponível em: < http://www.erebdfortaleza2014.ufc.br/gt/GT4/A\%C3\%87\%C3\%830\%20CUL TURAL\%20EM\%20BIBLIOTECAS.\%20conceitos\%20e\%20considera\%C3\%A7\% C3\%B5es.pdf>. Acesso em: 04 ago. 2014.

TRIVIÑOS, Augusto N. S. Introdução à pesquisa em ciências sociais: a pesquisa qualitativa em educação. São Paulo: Atlas, 1987.

VITORINO, Elizete Vieira. Competência informacional do profissional da informação bibliotecário: construção social da realidade. Enc. Bibli: R. Eletr. Bibliotecon. Ci. Inf., Florianópolis, n. 24, p. 59-71, 2º sem. 2007. Disponível em: $<$ https://periodicos.ufsc.br/index.php/eb/article/view/15182924.2007v12n24p59>. Acesso em: 04 ago. 2014.

WEITZEL, S. R. Critérios para seleção de documentos eletrônicos na Internet. In: CONGRESSO BRASILEIRO DE BIBLIOTECONOMIA E DOCUMENTAÇÃO, 19., Porto Alegre, 2000. Anais... Porto Alegre: PUCRS, 2000. Disponível em: <http://eprints.rclis.org/6491/1/Simone.pdf>. Acesso em: 14 abr. 2014. 